\title{
Beyond the HPA axis: progesterone-derived neuroactive steroids in human stress and emotion
}

\section{Michelle M. Wirth*}

Department of Psychology, University of Notre Dame, Notre Dame, IN, USA

\section{Edited by:}

Hubert Vaudry, University of Rouen, France

\section{Reviewed by:}

Rafael Vazquez-Martinez, University of Cordoba, Spain

Nicolas Vitale, CNRS, France

\section{*Correspondence:}

Michelle M. Wirth, Department of

Psychology, University of Notre

Dame, 123B Haggar Hall, Notre

Dame, IN 46556, USA.

e-mail:mwirth@nd.edu
Stress and social isolation are well-known risk factors for psychopathology. However, more research is needed as to the physiological mechanisms by which social support buffers the impacts of stress. Research in animal models suggests important roles for progesterone $(P)$ and its product, the neuroactive steroid allopregnanolone (ALLO), in stress and psychopathology. These hormones are produced in brain and periphery during stress in rodents, and down-regulate anxiety behavior and hypothalamic-pituitary-adrenal axis activity. Human clinical populations, including depressed patients, have alterations in ALLO levels, but it is unclear whether these basal hormone level differences have clinical import. To begin to address this question, this review examines the role of P and ALLO in stress physiology, and the impact of these hormones on mood, in healthy humans. Evidence largely supports that P and ALLO increase during stress in humans. However, P/ALLO administration appears to cause only mild effects on mood and subjective anxiety, while exerting effects consistent with gamma-aminobutyric acid receptor modulation. Additionally, $\mathrm{P}$ is linked to motivation for affiliation/social contact; $\mathrm{P}$ (and ALLO) release may be especially responsive to social rejection. These observations lead to the novel hypothesis that stress-related P/ALLO production functions not only to down-regulate stress and anxiety, but also to promote social contact as a long-term coping strategy. Malfunctioning of the P/ALLO system could therefore underlie depression partly by decreasing propensity to affiliate with others.

Keywords: progesterone, allopregnanolone, $3 \alpha$-hydroxy- $5 \alpha$-pregnan-20-one, stress, affiliation, social motivation, psychopathology, depression

\section{INTRODUCTION: THE IMPORTANCE OF PROGESTERONE-DERIVED HORMONES IN HUMAN EMOTION AND PSYCHOPATHOLOGY}

Stress is a part of life for all vertebrate animals. The physiology of stress is of utmost importance to study, given decades of research connecting stress to a host of health issues, ranging from cardiovascular health to immune function to psychopathological states such as depression. While the fields of behavioral and cognitive neuroscience tackle the neural pathways of stress and the effects of stress hormones on the brain, researchers in clinical psychology and psychiatry have been exploring the links between stress physiology and psychopathology; social and personality psychologists increasingly study human stress hormones in the context of various social situations. Another growing topic of research concerns the impact of social isolation and social support on health, including how seeking affiliation (positive social contact) and/or strengthening social bonds may help protect against adverse effects of stress.

Two major stress systems have been well-studied: the sympathetic nervous system (SNS) and the hypothalamic-pituitaryadrenal (HPA) axis, which gives rise to glucocorticoid hormones. To date, most research on stress physiology in humans has focused on the HPA axis, particularly the glucocorticoid hormone cortisol, which can be measured non-invasively in saliva. However, many other stress-related hormones exist. Another steroid hormone, progesterone $(\mathrm{P})$, is best known for its functions in mammalian reproduction. However, $\mathrm{P}$ and P-derived hormones also play important roles in stress and in psychological disease states. $\mathrm{P}$ is metabolized to other steroid hormones, including allopregnanolone (ALLO), which have actions on neurons, causing effects that are relevant for stress, emotion, and behavior. As evidence for their importance to the brain, P and ALLO are produced not only by peripheral glands (e.g., ovary; adrenal gland), but also in the brain itself (Paul and Purdy, 1992).

The role of these hormones in stress, along with their effects on neuronal transmission, have been studied for decades in animal models. More recently, evidence has emerged that $\mathrm{P}$ and ALLO are involved in human psychopathology. For reviews of the growing literature on neurosteroids and psychopathology (see van Broekhoven and Verkes, 2003; Pisu and Serra, 2004; Dubrovsky, 2006; Eser et al., 2006; N-Wihlback et al., 2006; Girdler and Klatzkin, 2007; Longone et al., 2008).

$\mathrm{P}$ and ALLO have been implicated in mood and anxiety disorders, most notably major depressive disorder (MDD), but also Premenstrual Dysphoric Disorder (PMDD), Generalized Anxiety Disorder, Post-Traumatic Stress Disorder (PTSD), and other illnesses (Brambilla et al., 2003; van Broekhoven and Verkes, 2003; Pisu and Serra, 2004; Amin et al., 2006; Dubrovsky, 2006; Eser et al., 
2006; Marx et al., 2006; Rasmusson et al., 2006; Uzunova et al., 2006; Girdler and Klatzkin, 2007). In laboratory animals, ALLO and other neurosteroids influence stress and anxiety, sleep, sexual behavior, and memory, all of which are involved in the symptomatology of depression (Dubrovsky, 2006). Multiple studies have shown decreased levels of ALLO in the plasma and cerebrospinal fluid (CSF) of MDD and PTSD patients, as well as in women with premenstrual syndrome or PMDD (Bicikova et al., 1998; Girdler et al., 2001; van Broekhoven and Verkes, 2003; Rasmusson et al., 2006). Interestingly, the decreased ALLO levels seen in depression normalize with treatment with selective serotonin reuptake inhibitors (SSRIs) or other antidepressant drugs (Romeo et al., 1998; Uzunova et al., 1998; Strohle et al., 1999; although not with non-pharmacological treatments; Schule et al., 2004; Baghai et al., 2005). ALLO injections exert antidepressant-like effects in rodents (e.g., in a forced swim test), and SSRIs normalize a decrease in ALLO seen after prolonged social isolation in rodents, a rodent model of depression (Guidotti et al., 2001; Rodriguez-Landa et al., 2007). Thus, there is some evidence that decreased ALLO levels may be a feature of MDD with clinical significance.

Taken together, the evidence strongly points to a connection between ALLO and depression along with other psychological disorders. However, it is unclear what causal relationship these hormones hold with psychopathology. Do low ALLO levels confer risk for developing depression? Or are hormonal changes a consequence of the disease? Will targeting ALLO help alleviate depression, or are the lower ALLO levels a "side effect" of the disorder with little or no clinical significance? Understanding the causal relationship between ALLO and depression is crucial in order to develop new treatments and/or identify novel risk factors for this disease. However, to date there has been very little basic research on the role of these hormones in the human stress response. In order to understand the role P and/or ALLO play in psychopathology, it is necessary to first understand the functions of these hormones in stress, mood, and motivated behavior in healthy humans.

One connection between ALLO and depression may involve social support and isolation. As social connectedness has welldocumented effects on health and disease, much research has focused on the physiological mechanisms by which social affiliation and bonding help buffer the effects of stress and reduce risk of psychopathology. Oxytocin, endogenous opioids, and the HPA axis are among the physiological systems implicated in affiliation and bonding and their stress-protective effects. Recently, evidence has also emerged linking $\mathrm{P}$ and motivation to affiliate (Schultheiss et al., 2004; Wirth and Schultheiss, 2006; Brown et al., 2009; Maner et al., 2010). One behavioral function that $\mathrm{P}$ (by itself, and/or via conversion to ALLO) may play in stress reduction is to promote social affiliation or bonding with conspecifics. If so, part of the import of ALLO levels in depression might be that lower ALLO levels are connected with depressed individuals' social isolation, a feature of depression which puts individuals at greater risk for worsened mental and physical health.

This review will first briefly survey evidence from non-human animals that $\mathrm{P}$ and ALLO are both stress-responsive (i.e., they increase during stress) and stress-reducing (they down-regulate stress and anxiety). Next, available literature will be reviewed to speak to whether/how $\mathrm{P}$ and ALLO are affected by stress and in turn affect subjective stress/anxiety in healthy humans. In addition, this review will highlight recent findings from personality and social psychology linking $\mathrm{P}$ with social affiliation and rejection. This evidence is crucial to shed light on the role P/ALLO play in mental health and disease, as social isolation is a key risk factor for psychopathology, and seeking social support may be an important buffer against the effects of stress. Finally, the current knowledge from neuroscience, clinical psychology, and social psychology will be integrated in a broadened theoretical framework for function of $\mathrm{P}$ and ALLO during stress, and a plan for crucial future research will be described.

\section{NEUROACTIVE STEROIDS AND STRESS: BACKGROUND AND RESEARCH IN LABORATORY ANIMALS}

ALLO belongs to a subset of steroid (cholesterol-derived) hormones called neuroactive steroids, which are produced in the brain and have "fast" actions on neurons (i.e., changing neuronal excitation) via membrane-bound receptors. This is in contrast to actions of steroid hormones on "classical" steroid receptors, which reside inside the cytoplasm and initiate changes in gene transcription, leading to slower and more prolonged responses.

In rodents, $\mathrm{P}$ and ALLO levels rise in the brain and plasma during stress, including swim stress, foot shock, and carbon dioxide stress (Purdy et al., 1991; Barbaccia et al., 2001). These stressrelated increases are reminiscent of increases in a better-known class of stress hormones, glucocorticoids, produced by the HPA axis. Unlike glucocorticoids, however, stress-induced P and ALLO increases originate not only from the adrenal gland, but from the brain itself (Purdy et al., 1991; Paul and Purdy, 1992). Brain levels of these hormones increase during stress even in adrenalectomized, gonadectomized animals (Paul and Purdy, 1992); neurons and glial cells throughout the brain contain the enzymes necessary for ALLO production (Celotti et al., 1992; Rupprecht, 1997; Magnaghi, 2007). P is an early step in the steroid hormone synthesis pathway which begins with cholesterol. ALLO, which is variously known as $3 \alpha$-hydroxy-5 $\alpha$-pregnan-20-one, $3 \alpha, 5 \alpha$ tetrahydroprogesterone, or $3 \alpha, 5 \alpha$-THP, is synthesized from $\mathrm{P}$ in a two-step pathway requiring the enzymes $5 \alpha$-reductase and $3 \alpha$ hydroxysteroid dehydrogenase (Figure 1). These enzymes are found in the adrenal, gonad, and throughout the brain, including in the cerebral cortex, hippocampus, and hypothalamus (Compagnone and Mellon, 2000), structures involved in regulating emotion and memory formation, among other functions.

$\mathrm{P}$ or ALLO administration has anxiolytic and sedative effects in rodents, as well as in humans (Wieland et al., 1991; Paul and Purdy, 1992; Bitran et al., 1995; Soderpalm et al., 2004; Timby et al., 2006). These effects appear to result from the action of ALLO at receptors for gamma-aminobutyric acid (GABA), the brain's primary inhibitory neurotransmitter. As a positive allosteric modulator of GABA-A receptors, ALLO enhances GABA's effects on chloride ion $\left(\mathrm{Cl}^{-}\right)$influx, which causes longer-lasting inhibitory post-synaptic potentials. At high doses, ALLO can also act as a GABA-A agonist in the absence of GABA (Majewska et al., 1986; Harrison et al., 1987; Paul and Purdy, 1992; Shu et al., 2004). As a GABA modulator, ALLO has similar efficacy and potency as benzodiazepines (Harrison and Simmonds, 1984; Majewska et al., 1986), although it does not interact with GABA receptors at the benzodiazepine 


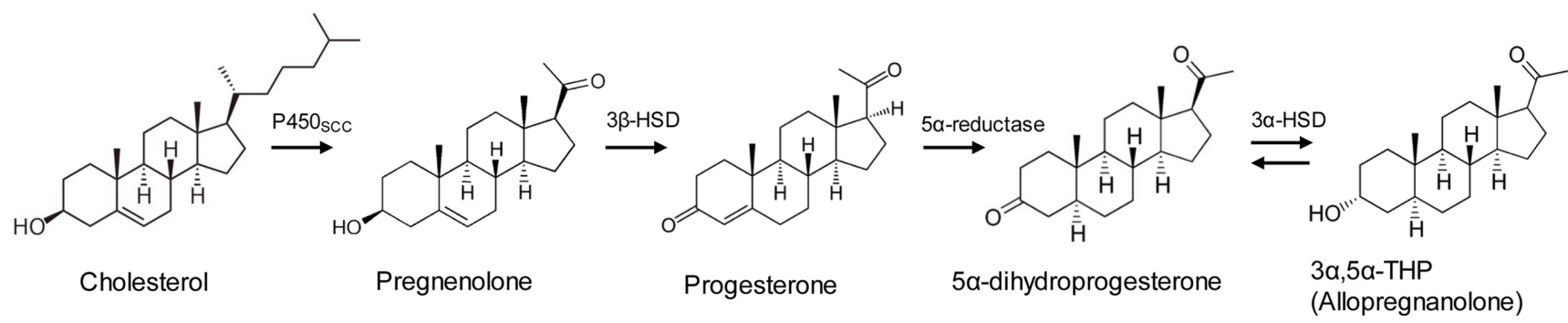

FIGURE 1 | Synthesis pathway for progesterone and allopregnanolone. For a complete steroid synthesis pathway including other neurosteroids, see (Morrow, 2007).

binding site (Brot et al., 1997; Lambert et al., 2003; Akk et al., 2004a). Thus, $P$ and ALLO are important agents of neuronal inhibition in the mammalian brain, exerting neurochemical effects similar to classes of drugs used to treat anxiety.

Given ALLO's effects on GABA activity and anxiety behavior, the stress-induced increases in P and ALLO very likely play roles in down-regulating or "turning off" the effects of stress. In support of this idea, ALLO has been shown to affect the HPA axis: ALLO administration down-regulates gene transcription for the HPA axis hormones corticotrophin-releasing hormone (CRH) and arginine vasopressin (AVP) in rodents (Patchev et al., 1994, 1996). These effects suggest that ALLO release during stress is yet another mechanism (in addition to HPA axis negative feedback, etc.) to keep this stress hormone system in check.

The anti-stress and anxiolytic effects of $\mathrm{P}$ are thought to be mediated by the conversion of P to ALLO, and ALLO's actions at GABA-A receptors, rather than by effects on intracellular $\mathrm{P}$ receptors. For example, blocking $\mathrm{P}$ receptors with RU-486 did not diminish anxiolytic responses to $\mathrm{P}$ treatment (Bitran et al., 1995). Also, mice lacking $5 \alpha$-reductase (and therefore the ability to synthesize ALLO from P) lacked some (but not all) of the anxiolytic and sedative responses to $\mathrm{P}$ seen in wild-type controls (Frye et al., 2004). However, there is some evidence that $\mathrm{P}$ may also exert anti-anxiety effects via mechanisms mediated by classical intracellular P receptors (Auger and Forbes-Lorman, 2008) ${ }^{1}$. Further research must tease apart the behavioral consequences of actions of P/ALLO on classical steroid receptors vs. membranebound receptors, to better understand the mechanisms by which these hormones affect stress and anxiety.

Other neurosteroids are also present and active in the brain. A stereoisomer of ALLO, pregnanolone ( $3 \alpha$-hydroxy- $5 \beta$-pregnan20 -one, or $3 \alpha, 5 \beta$-THP) is also a positive modulator at GABA receptors, although some researchers have found that ALLO is more potent (Norberg et al., 1987; Bitran et al., 1991; Zhu et al., 2001). The $3 \alpha$-reduced products of deoxycorticosterone (DOC) also increase GABA activity. Lack of commercially available antibodies

\footnotetext{
${ }^{1}$ ALLO does not bind progesterone receptors (PR). However, the intermediate steroid step between $\mathrm{P}$ and ALLO, $5 \alpha$-dihydroprogesterone ( $5 \alpha$-DHP), has activity at $\mathrm{PR}$, and the conversion step from $5 \alpha$-DHP to ALLO (mediated by $3 \alpha$-hydroxysteroid dehydrogenase) is bi-directional (Compagnone and Mellon, 2000; Dong et al., 2001) Therefore, $\mathrm{P}$ may cause activation of PR via $\mathrm{P}$ itself or $5 \alpha-\mathrm{DHP}$, as well as changes to GABA activity via ALLO.
}

for these other neurosteroids is one reason that few studies have measured neurosteroids other than ALLO. This review focuses on ALLO because it appears to be the most potent positive GABA modulator among the neurosteroids, it is the best-studied neurosteroid to date, and there is evidence that humans have higher concentrations of ALLO than of other neurosteroids or its isomers (Parizek et al., 2005; Porcu et al., 2009).

To summarize, cellular and molecular neuroscience work in laboratory animals has established $\mathrm{P}$ and $\mathrm{ALLO}$ as stress-responsive, stress-reducing hormones. In rodents, $\mathrm{P}$ and ALLO increase in both blood and brain during stress; in turn, these hormones exert powerful inhibitory effects on neuronal transmission, causing antianxiety and sedative effects; they also down-regulate the HPA axis. It is logical to suspect that the same would be true in humans, i.e., $\mathrm{P}$ and ALLO increase during stress and reduce stress and anxietya supposition with far-reaching clinical implications. However, species differences in stress-related hormonal systems are possible. This review will synthesize evidence that speaks to whether $\mathrm{P}$ and ALLO are similarly stress-responsive and stress-reducing in humans.

One important issue to consider when conducting neuroendocrinology research in humans is whether peripheral levels of the hormone reflect brain levels; this is particularly an issue with peptide hormones. Fortunately, $\mathrm{P}$ and ALLO are steroid hormones which can cross the blood-brain barrier. Although the bloodbrain barrier may also control entry of steroids via active transport, studies in rodents report that plasma and brain levels of both $\mathrm{P}$ and ALLO are strongly correlated (Barbaccia et al., 1997, 2001). Also, in at least one study, ALLO levels were comparable in human blood and CSF (Kim et al., 2000). Though more studies are needed, this evidence suggests that measurement of blood levels of ALLO does give researchers meaningful information about brain levels of ALLO.

A related issue, however, is determining the source of $\mathrm{P}$ and ALLO increases measured in blood (or in CSF, for that matter), as these hormones are produced both by the brain and peripheral glands. As steroid hormones, presumably they may travel across the blood-brain barrier in both directions; thus, P/ALLO produced in the brain could theoretically enter the bloodstream. However, in rodents a much greater amount of $\mathrm{P}$ is produced in the periphery compared to the brain (Purdy et al., 1991). If humans are similar, it seems unlikely that a change in brain production of $\mathrm{P}$ would be detectable in plasma. Hence, increases in 
plasma P or ALLO seen in humans probably originate from peripheral glands (e.g., the adrenal gland.) Nonetheless, these increases are potentially important for stress and behavior, as steroid hormones of peripheral origin do enter the brain and exert effects (see, for example, the large literature on effects of glucocorticoids on memory; Lupien et al., 2007; de Quervain et al., 2009).

It is still possible that neurosteroids are produced selectively and locally in the brain in amounts too small to detect in the bloodstream (or CSF), but that have behaviorally relevant effects by acting at local brain sites. Unfortunately, there are no methods currently available to measure steroid levels locally in the living human brain. What can be done with current methods, however, is to measure levels of P and ALLO that are bathing the brain (as blood levels seem to reflect CSF levels), and likely having widespread effects.

\section{STRESS-RESPONSIVE? PROGESTERONE AND ALLOPREGNANOLONE RESPONSES TO STRESS IN HUMANS}

Very few studies to date have systematically tested the effects of stress on P and ALLO levels in humans. As a crucial first step, Genazzani et al. (1998) examined effects on plasma P and ALLO after a CRH or ACTH challenge in healthy women in the follicular phase of the menstrual cycle, a time of low levels of circulating $\mathrm{P}$ and ALLO. Within $60 \mathrm{~min}$ after an intravenous bolus of either CRH or ACTH, plasma concentrations of both P and ALLO increased significantly. Thus, the releasing and tropic hormones of the HPA axis, which are triggered by stress, cause production of $\mathrm{P}$ and ALLO. The most likely source of this $\mathrm{CRH}$ - and ACTH-responsive $\mathrm{P}$ and ALLO is the adrenal gland (see discussion above).

Girdler and colleagues have conducted several studies investigating the roles of $\mathrm{P}$ and ALLO in premenstrual dysphoric disorder (PMDD). As part of this work, they have exposed women to laboratory stressors and collected blood for measurement of ALLO. In one study, luteal-phase women with PMDD and healthy controls underwent a laboratory stressor consisting of making an audiotaped speech and a completing a challenging arithmetic task (Girdler et al., 2001). Though overall, healthy women did not appear to have a significant increase in ALLO due to this stressor, PMDD and control groups differed in their responses to stress: significantly more (83\%) control subjects had increased ALLO after stress compared to PMDD subjects (42\%; Girdler et al., 2001). In addition to yielding clues as to the pathophysiology of PMDD, this study provided further evidence that ALLO increases during stress in humans. However, only one post-stress blood sample was collected (17 min after stress onset); it is possible that the peak ALLO response was not captured. Also, time of day that subjects were tested varied. This could have introduced "noise" in the P/ALLO stress response data and obscured effects, similarly to how larger effect sizes are found for HPA/cortisol responses to stress in the afternoon or evening (when basal cortisol is low and stable) compared to the morning (Dickerson and Kemeny, 2004).

Interestingly, in the combined (PMDD and control) sample, Girdler et al. (2001) also documented a negative correlation between cortisol and ALLO both at baseline/rest and after stress. This finding suggests that, as in rats, ALLO down-regulates the HPA axis in humans.
A later study from this group (Klatzkin et al., 2006b) compared PMDD-sufferers and controls with and without prior depression on ALLO responses to a modified Trier Social Stress Test (TSST; Kirschbaum et al., 1993), involving a speech delivered to a panel of judges, followed by a mental arithmetic task. In this study, samples were collected 30 and $60 \mathrm{~min}$ after stressor onset. Again a group difference was found in direction of ALLO responses to stress: women with a prior history of depression were more likely to have lower ALLO after stress compared to before stress. However, control subjects did not exhibit a significant increase in ALLO due to stress. As with the 2001 study, it is unclear whether the findings indicate that, in general, ALLO does not increase following stress in humans, or whether the few samples collected failed to pick up on a short-lived response. Also, although we may assume a rise in $\mathrm{P}$ would drive an increase in ALLO, $\mathrm{P}$ was not measured in these studies.

As these studies were appearing, evidence was emerging that $\mathrm{P}$ does in fact increase in response to stress in humans. The author and colleagues found positive correlations between $\mathrm{P}$ and cortisol in healthy human subjects across four separate studies, some of which included arousal of emotional states, but not standard laboratory stressors (e.g., public speaking; Wirth et al., 2007). These correlations were robust in men and in women taking oral contraceptives (i.e., with suppressed ovarian production of P), but not in cycling women. This pattern of results is consistent with the data collected by Genazzani et al. (1998) demonstrating adrenal production of $\mathrm{P}$ during a challenge: in cycling women, ovarian fluctuations in $\mathrm{P}$ appear to "drown out" the relationship otherwise seen between adrenal cortisol and $\mathrm{P}$, which may be released into the bloodstream simultaneously. In addition to simple correlations, positive bi-partial correlations (Cohen and Cohen, 1983) were seen between $\mathrm{P}$ and cortisol in all four studies, indicating parallel changes (whether increases or decreases) in these two hormones from measurement point to measurement point. Furthermore, findings from one of the studies included in the 2007 meta-analysis suggested that P might especially be responsive to stressors related to affiliation or rejection stress (Wirth and Schultheiss, 2006). These findings will be discussed in more depth in "Progesterone in affiliation-seeking," below.

More recent evidence directly shows that stress can cause $\mathrm{P}$ increases in humans. As part of a larger study investigating hypotheses related to HPA axis function (at University of Wisconsin - see Acknowledgments), we collected saliva samples before and after placement of intravenous catheters, a physical (pain) as well as social stressor (two experimenters in the room watching as the nurse placed the lines). Healthy subjects completed two sessions $48 \mathrm{~h}$ apart, both including placement of i.v. catheters at approximately 16:45-17:00, following a period of rest and acclimation to the hospital environment. In a subset of subjects for which salivary P and cortisol were analyzed, a P response to stress was evident that closely paralleled that of cortisol, including similar patterns of habituation of the responses from the first to the second session (M. M. Wirth, H. C. Abercrombie, and R. M. Hoks, unpublished data; Figure 2). Hence, $P$ responds to stress in humans in a fashion that closely parallels the better-studied stress hormone cortisol. It may follow that ALLO also responds to stress; however, ALLO was not measured in these samples. 

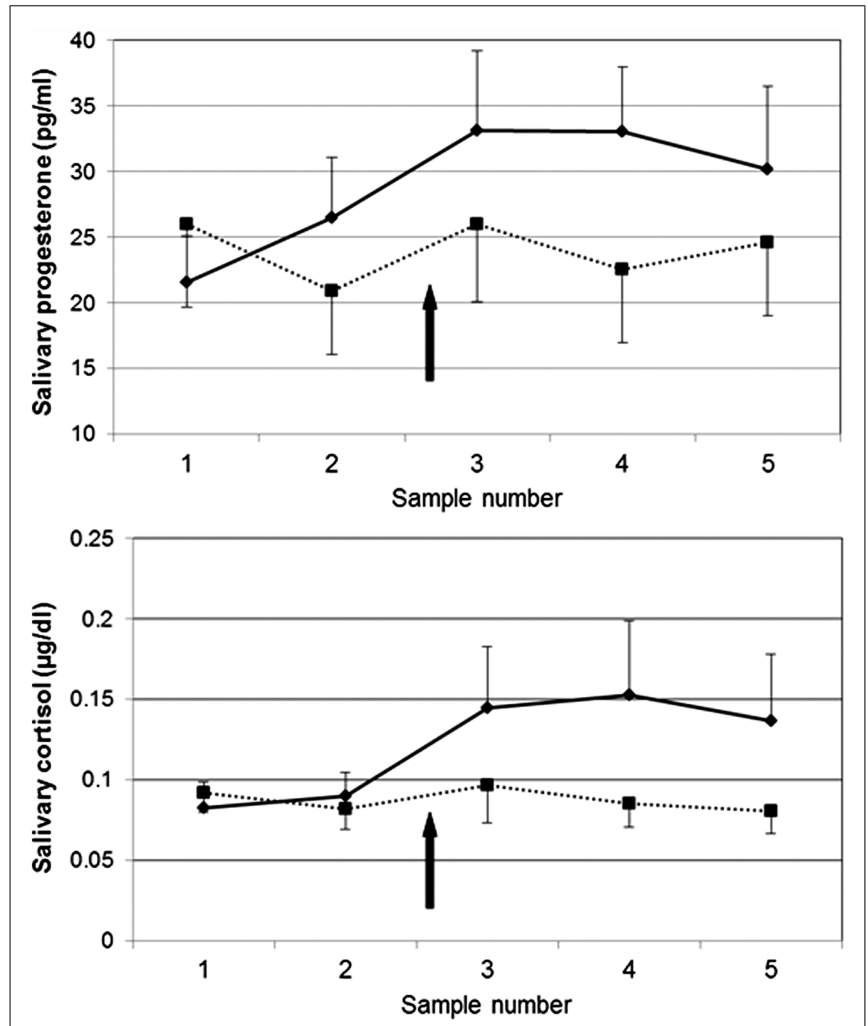

FIGURE 2 | Salivary progesterone (top) and cortisol (bottom) responses to venipuncture stress in humans in two sessions, $48 \mathrm{~h}$ apart. Solid line $=$ session 1 ; dashed line $=$ session 2 . Saliva samples were collected 55 and $25 \mathrm{~min}$ before and 10, 20, and $30 \mathrm{~min}$ after venipuncture. $N=11$; all women (4) were taking hormonal contraceptives. In session 1 , progesterone was significantly higher post-stress (sample \#3) compared to baseline (sample \#1), $t(11)=2.29, p<0.05$.

A short report which appeared in 2004 was the first to demonstrate an ALLO increase during a more naturalistic ("real-world") stressor in humans. Students had elevated ALLO during their oral Ph.D. examination as compared to 4 weeks or $45 \mathrm{~min}$ prior to, or 4 weeks following, the examination. Also elevated were cortisol and peripheral benzodiazepine receptors, which play a role in steroid synthesis (Droogleever Fortuyn et al., 2004).

Recently, the first studies systematically examining both $\mathrm{P}$ and ALLO responses to a potent psychosocial stressor (the TSST) were published (Childs and de Wit, 2009; Childs et al., 2010a). Healthy men, women in the follicular phase, and women in the luteal phase of the menstrual cycle underwent a TSST and a control task on separate days while blood samples were collected at multiple timepoints after the stressor/task. Women in the follicular phase and men had a significant increase in $\mathrm{P}$ due to stress compared to control, while luteal-phase women (with roughly 10-fold higher baseline P levels than men or follicular-phase women) did not have a significant increase in $\mathrm{P}$ due to stress (Childs et al., 2010a). Other studies by this group also found a significant plasma $\mathrm{P}$ increase due to stress in men (Childs and de Wit, 2009; Childs et al., 2010b, placebo group). On the other hand, only luteal-phase women had a significant increase in ALLO in the stress session compared to the control session (Childs et al., 2010a). Across all three groups,
$\mathrm{P}$ and ALLO were not correlated. These data seem to suggest that, unlike in rodents, $\mathrm{P}$ vs. ALLO responses to stress are dissociated in humans, and ALLO responses to stress only occur in women in a specific cycle phase when $\mathrm{P}$ and ALLO production is high. It is also possible (though difficult to test) that in humans, ALLO concentrations rise in the brain but not in the periphery during stress.

There are numerous factors that complicate interpretation of these data. One issue, which the authors acknowledge, is that study sessions took place in the morning, when steroid hormone levels tend to be high and variable. The impact of time of day is especially clear in the cortisol data; the TSST had no significant effect on follicular- or luteal-phase women's cortisol in this sample, evidently due to a steep decline in cortisol over the course of the session, which is typical of morning hours. The morning time of testing could similarly have obscured effects of stress on $\mathrm{P}$ and ALLO, although in the data shown, neither P nor ALLO levels appear to drop as rapidly as cortisol over the course of the session.

Also of note in these data is that plasma levels of ALLO were actually found to be three- to four-fold higher than levels of $\mathrm{P}$ in men and in follicular-phase women (luteal-phase women had, on average, roughly $60 \%$ as much ALLO as $\mathrm{P}$ ). This could represent an important difference between human and rat physiology, such that the bulk of circulating $\mathrm{P}$ in humans is quickly converted to ALLO. However, it is difficult to compare the P and ALLO data since the two hormones were assayed in two separate laboratories (Childs et al., 2010a). In earlier reports, plasma $\mathrm{P}$ concentrations were found to be roughly 10-fold higher than ALLO concentrations in women across the entire menstrual cycle (Genazzani et al., 1998), and approximately eight-fold higher in men and follicular-phase women, with a much greater difference in luteal-phase women (Pearson Murphy and Allison, 2000).

The research described thus far has been essential to further our understanding of the roles of P and ALLO in stress physiology in humans. However, future studies are needed to make firm conclusions about the behavior of these hormones during stress. Laboratory stressors should be administered in the late afternoon or evening hours for maximal capture of hormonal stress responses. Care should be taken with selection of analytical methods; evidence exists that liquid or gas chromatography followed by mass spectrometry has greater sensitivity and specificity for ALLO than radioimmunoassay, as well as being preferable for analysis of multiple neurosteroids at once (Cheney et al., 1995; Wolthers and Kraan, 1999; Vallee et al., 2000; Alomary et al., 2001). Another important factor to consider in investigations of hormonal stress responses is the presence in the blood of steroid hormone binding globulins. A proportion of $\mathrm{P}$ in the blood is, at any given time, bound to corticosteroid-binding globulin $(\mathrm{CBG})$ or albumin; CBG-bound $\mathrm{P}$ is prevented from crossing the blood-brain barrier (Compagnone and Mellon, 2000), or, presumably, being converted to ALLO. Differences in plasma concentrations of binding globulins between men and women in different cycle phases could affect P/ALLO ratios and ALLO responses to stress. Possible differences in women taking hormonal contraceptives should also be addressed.

In summary, evidence thus far largely, but not entirely, supports $\mathrm{P}$ and ALLO increases during stress in humans. Though 
pharmacological stimulation of the HPA axis with CRH or ACTH caused robust increases in both P and ALLO (Genazzani et al., 1998), application of laboratory stressors has produced mixed effects. P increases in response to the TSST were observed in men and in follicular-phase women, but not in luteal-phase women (Childs et al., 2010a). The author and colleagues observed close relationships between $\mathrm{P}$ and cortisol in emotion-arousal studies (Wirth et al., 2007) and in response to venipuncture stress (M. M. Wirth, H. C. Abercrombie, and R. M. Hoks, unpublished data). An ALLO increase was evident during Ph.D. examination in one study (Droogleever Fortuyn et al., 2004). However, in a larger study, ALLO stress responses were only evident in luteal-phase women (Childs et al., 2010a), and were only apparent in a subset of women in other studies (Girdler et al., 2001; Klatzkin et al., 2006b). Further work carefully selecting time of day and method of hormone analysis may help clarify whether P and ALLO are stress-responsive hormones in humans, as they are in rats.

\section{STRESS-REDUCING? EFFECTS OF EXOGENOUS PROGESTERONE AND ALLOPREGNANOLONE IN HUMANS}

Do P and ALLO exert similar anxiolytic or stress-reducing effects in humans as they do in laboratory animals? Evidence suggests that they do, although the effects may be less dramatic than what would be expected based on animal research.

When studying effects of exogenous $\mathrm{P}$, it is important to consider the length of time P and ALLO are both elevated in the blood (and therefore presumably in the CSF). P has a relatively long half-life, reported at 35-55 h (Wikipedia, 2011). Studies in humans generally use either oral or intramuscular administration of $\mathrm{P}$, in doses from 50 to $1000 \mathrm{mg}$. Both administration routes cause prolonged elevations in plasma levels of both P and ALLO, with ALLO increasing shortly after the increase in P. For example, in a study of effects of $\mathrm{P}$ on sleep in human males, a single oral dose of $300 \mathrm{mg}$ micronized $\mathrm{P}$ at $2130 \mathrm{~h}$ (before bed) caused blood $\mathrm{P}$ to be elevated for at least $3 \mathrm{~h}$ and ALLO for at least $8 \mathrm{~h}$, with both peaking around $90 \mathrm{~min}$ after administration (Friess et al., 1997). In a study utilizing intramuscular injection, males injected with 50 or $100 \mathrm{mg} P$ still had highly elevated plasma P $4 \mathrm{~h}$ following the injection (Childs et al., 2010b). Thus, though some P is rapidly metabolized into ALLO and other products, administration of $\mathrm{P}$ leads to long-lasting elevations of both $\mathrm{P}$ and ALLO in the bloodstream and presumably in the CSF as well.

Administration of $\mathrm{P}$ in humans has been associated with mild increases in fatigue, confusion, and sedation (Freeman et al., 1993; de Wit et al., 2001; Soderpalm et al., 2004; Klatzkin et al., 2006a). For example, Klatzkin et al. (2006a) administered $300 \mathrm{mg}$ oral micronized $\mathrm{P}$ to healthy women as well as PMDD patient groups with and without prior depression. This dose raised $\mathrm{P}$ to a level similar as seen in pregnancy, and increased ALLO levels 5- to 20 -fold. After controlling for effects of placebo on mood, P treatment was associated with increased confusion and fatigue and decreased confidence, as rated by study participants on a pre- and post-treatment Profile of Mood States (POMS) questionnaire, a commonly used measure of mood in which participants rate how much they feel a list of feelings right now on a 1-5 scale. Furthermore, women with PMDD reported a decrease in anxiety after $\mathrm{P}$ treatment (Klatzkin et al., 2006a). de Wit et al. (2001) used intramuscular injections of P, which cause increases in plasma $\mathrm{P}$ and ALLO levels that are less variable across individuals than oral P. Pre-menopausal, follicular-phase women receiving $100 \mathrm{mg}$ intramuscular $\mathrm{P}$ reported decreased vigor, friendliness, and arousal ratings on the POMS, consistent with sedative effects of $P$. In post-menopausal women, those receiving $100 \mathrm{mg}$ of $\mathrm{P}$ reported a delayed $(6 \mathrm{~h})$ increase in positive mood relative to placebo. No effects on subjective state were observed in post-menopausal women receiving lower doses of $\mathrm{P}(25 \mathrm{or} 50 \mathrm{mg})$. A later study by this group (Soderpalm et al., 2004) observed similarly mild effects on subjective state of $200 \mathrm{mg} P$ in men and women: only an increase in self-reported fatigue was observed, despite $\mathrm{P}$ concentrations in blood around or above those seen during pregnancy, and highly elevated ALLO.

These subtle effects on mood and anxiety are surprising given the effects of ALLO at the GABA-A receptor. Several factors could help explain this discrepancy. Questions may arise as to whether P/ALLO circulating in the bloodstream reached the brain. However, as noted previously, steroid hormones are chemically suited to cross the blood-brain barrier. In rodents, peripherally administered $\mathrm{P}$ and other steroids enter the brain and exert central effects (Karavolas et al., 1979; Wang et al., 1997); this is likely also true in humans (Uzunova et al., 2006). Furthermore, Soderpalm et al. (2004) do report impaired smooth pursuit (eye movements) in both men and women given $\mathrm{P}$ compared to placebo. Smooth pursuit is a measure of motor performance which is highly sensitive to GABA-active drugs such as benzodiazepines. Thus, these data indicate that peripheral $\mathrm{P}$ administration did exert central effects, presumably via conversion to ALLO either in the periphery and/or in the brain itself.

As for other factors that could explain the mild and inconsistent effects of P/ALLO increases on subjective state, de Wit and colleagues point out that subjects received acute doses of P; perhaps subjective effects only emerge after chronic exposure to high P/ALLO levels. Another possibility is that higher or lower doses of P/ALLO would exert a greater effect on subjective state. Many effects of hormones on neurons and on behavior observe an inverted U-shaped dose-response curve, e.g., the effects of corticosteroids on memory (de Kloet et al., 1999; Joels, 2006). It is possible that much smaller doses of $\mathrm{P}$ would produce greater effects on subjective state than the relatively high doses used in these studies. Circadian factors might also matter; $\mathrm{P}$ was administered in the morning in the studies reported by Klatzkin et al. (2006b); de Wit et al. (2001) and Soderpalm et al. (2004). Finally, effects of P/ALLO on subjective states could also depend on stress or emotional state, a point the authors raised in these reports.

This final point was addressed in a recent study by the same research group (Childs et al., 2010b). Healthy men were injected with 0 , 50, or $100 \mathrm{mg} \mathrm{P}$ and then exposed to the TSST. In this study, in the absence of stress, $\mathrm{P}$ had no effect on subjective mood. Interestingly, P treatment reduced some of the responses to stress, but increased others. $50 \mathrm{mg} P$ caused a decrease in the peak cortisol response to the stressor, and this dose attenuated the TSST-induced changes in self-reported vigor and drowsiness. Self-reported anger also returned to baseline faster with $50 \mathrm{mg}$ P compared with placebo. Similarly, $100 \mathrm{mg}$ P reduced TSSTinduced changes in vigor and drowsiness, but had no effects on 
anger or cortisol. On the other hand, both doses increased blood pressure, and $50 \mathrm{mg}$ also increased plasma noradrenaline. Thus, $P$ caused mixed effects on stress-related responses in this study. The authors help explain these mixed findings with evidence that ALLO and other GABA-A modulators exert bimodal/paradoxical effects, both in humans and laboratory animals: low doses have been found to increase negative mood and anxiety-like behaviors, whereas high doses reduce anxiety. It is also possible that the brain has various compensatory responses to exogenous neurosteroids that would not be evident with endogenous release of these hormones.

Along these lines, Andreen et al. (2009) point out that anxiety, irritability and aggression can result from treatment with progestins and their associated GABA-active steroids in humans and other animals. The authors cite evidence that negative mood symptoms in women with PMDD correspond to levels of $\mathrm{P}$ and ALLO in the menstrual cycle, and that hormone replacement therapy with progestin components can induce negative mood in post-menopausal women. The authors argue that $\mathrm{P}$ and ALLO have adverse effects on mood (e.g., generating anxiety) at levels similar to luteal-phase levels in cycling women; at lower or higher levels these hormones may have no effect or have anxiolytic effects. This approach may help explain why $\mathrm{P}$ administration leading to moderate plasma increases in P and ALLO resulted in an increase in the response of the amygdala, a key brain structure for negative affect, to fear and threat stimuli in healthy women (van Wingen et al., 2008).

Possibly more reliably than effects on subjective mood, neurosteroids elicit changes in measures of motor performance sensitive to sedatives, such as smooth pursuit and saccadic eye velocity. For example, Soderpalm et al. (2004) found decreased smooth pursuit eye movements in both men and women given P. Sundstrom et al. (1998) demonstrated a reduction in saccadic eye velocity in healthy women given three 15-mg injections of pregnanolone ( $3 \alpha, 5 \beta$-THP; ALLO's stereoisomer) in both the follicular and luteal phases of the menstrual cycle. Notably, the effects of pregnanolone were absent in luteal-phase women with premenstrual syndrome, suggesting a difference in GABA signaling. More recently, in the only published report of ALLO itself administered to humans (Timby et al., 2006), this group showed decreases in saccadic eye velocity parameters after a total IV dose of $0.9 \mathrm{mg} / \mathrm{kg}$ ALLO in follicular-phase women. Women also reported increased sedation around the time of peak effects on saccadic eye velocity. Moreover, both subjective sedation ratings and saccadic measures correlated significantly with plasma ALLO levels (Timby et al., 2006). These findings strongly suggest that P-related neurosteroids administered peripherally do enter the brain and exert central effects consistent with their known actions at GABA receptors.

Effects of exogenous neurosteroids on cognitive functions have also been demonstrated, again consistent with GABAergic activity; other substances which have GABA-facilitatory effects are well-known to be disruptive to memory formation (e.g., alcohol; barbiturates; benzodiazepines). $\mathrm{P}$ administration was associated with impaired verbal recall, and greater impairment was associated with higher plasma ALLO levels (Freeman et al., 1993). In addition, recent studies report that $\mathrm{P}$ or ALLO administration to humans caused mild impairment of memory for social-emotional stimuli (emotional faces; van Wingen et al., 2007) or free recall of words from a list (Kask et al., 2008). These memory effects may be mediated by the impact of P/ALLO on memory-involved brain regions such as the amygdala, hippocampus, and fusiform gyrus (van Wingen et al., 2007). These findings parallel effects of ALLO on cognition in rodents: ALLO disrupted memory formation in a Y-maze task in rats (Ladurelle et al., 2000) and disrupted spatial learning in a Morris water maze (Johansson et al., 2002; Silvers et al., 2003).

\section{PROGESTERONE AND AFFILIATION-SEEKING}

$\mathrm{P}$ and ALLO regulate mammalian reproductive behavior; $\mathrm{P}$ is wellknown for its facilitative role in both sexual and maternal behavior in female rodents. Of note, these hormones also influence the expression of other social-affiliative behaviors (Frye et al., 2006). For example, ALLO administration in ovariectomized, estradioltreated female rats increased the time they spent in proximity to male rats; blocking ALLO had the reverse effect (Frye et al., 1998). Furthermore, at some doses, ALLO reduces aggression toward another rodent (Miczek et al., 2003; Frye et al., 2006). These observations point to a possible role for $\mathrm{P}$ and ALLO in promoting affiliation, or positive social contact with conspecifics. There is also evidence for a role of ALLO in stress related to lack of affiliation or social contact. Social isolation (which is used as a rodent model of depression or chronic stress) leads to a decrease in brain and plasma $\mathrm{P}$ and ALLO concentrations, as well as changes in GABA transmission and responses to ethanol that appear to be mediated by ALLO (Serra et al., 2007). Also, central administration of ALLO reduces separation distress in rat pups (Zimmerberg et al., 1994).

Schultheiss and colleagues found evidence for a connection between $\mathrm{P}$ and affiliation in humans. In one study, implicit affiliation motivation - a personality psychology construct measuring drive for friendly, warm contact with others - was increased in women taking oral contraceptives containing progestins, as well as in cycling women in the luteal phase, a time in the cycle of high P (as well as ALLO) levels (Schultheiss et al., 2003). This correlational finding prompted experimental studies in which implicit affiliation motivation was manipulated using film excerpts, and effects on $\mathrm{P}$ and other hormones were investigated (Schultheiss et al., 2004; Wirth and Schultheiss, 2006). Among other findings, a "rejection"-themed film excerpt designed to produce affiliationrelated stress caused increases in $\mathrm{P}$ as well as cortisol. Further, among participants exposed to this affiliation-related stressor, baseline (pre-film) affiliation motivation predicted stress-related increases in P (but not cortisol; Wirth and Schultheiss, 2006). This finding suggests that participants more concerned with affiliation were more impacted by the affiliation-related stressor, and hints at a relationship between $\mathrm{P}$ and affiliation-related stress.

Given the literature implicating $\mathrm{P}$ and ALLO in the downregulation of stress, it can be hypothesized that stress-induced $\mathrm{P}$ (and ALLO) increases may partly function to promote affiliation as a stress-coping strategy, similarly to the "tend and befriend" hypothesis proposed by Shelley Taylor and colleagues regarding oxytocin (Taylor et al., 2000). Intriguingly, other neuroactive substances linked to affiliation and social bonding, such as opioids and oxytocin, are also released during stress and exert anxiolytic effects 
(Akil et al., 1984; Kalin et al., 1988; Hashimoto et al., 1989; UvnasMoberg et al., 1994; Uvnas-Moberg, 1998a; da Silva Torres et al., 2003; Heinrichs et al., 2003; Onaka, 2004; Ribeiro et al., 2005). It is possible that ALLO release during stress, while down-regulating stress in the short term by its actions at GABA-A receptors, also ameliorates stress by promoting affiliation and social bonding as a coping strategy (Wirth and Schultheiss, 2006).

Further work has continued to support a role for $\mathrm{P}$ in affiliation and bonding processes in humans. Brown et al. (2009) had same-sex pairs of participants engage in a task designed to promote closeness vs. a neutral task. The closeness induction was associated with an increase in salivary $\mathrm{P}$ levels, mirroring effects of a positive affiliation-themed film excerpt in the Schultheiss et al. (2004) study. Furthermore, P increases were associated with each participant's stated willingness to sacrifice for their partner in the study (Brown et al., 2009). Recent data collected by Brown and others supports a connection between $\mathrm{P}$ and pro-social (helping) behavior, including evidence that $\mathrm{P}$ is involved in the beneficial effects of helping behavior on cardiovascular recovery from stress (Brown and Brown, 2011; Smith, 2011).

Maner et al. (2010) measured salivary P before and after two different social rejection or exclusion paradigms. They found that the personality traits determined how $P$ responded to these manipulations. Those high in social anxiety showed a drop in $\mathrm{P}$ in response to priming exclusion/rejection, which the authors interpret as indicative of the lower motivation to affiliate expected in the socially anxious. In a separate study, those high in rejection sensitivity showed increased $\mathrm{P}$ after a realistic rejection manipulation after which participants were given an opportunity to spend time with others (Maner et al., 2010). These findings dovetail with Wirth and Schultheiss (2006) and add to the evidence of a relationship between $\mathrm{P}$ and motivation to affiliate, perhaps particularly in the context of rejection or exclusion.

It is unknown whether this relationship between $\mathrm{P}$ and affiliation depends on actions of $\mathrm{P}$ at classical intercellular $\mathrm{P}$ receptors, actions of ALLO at GABA-A receptors, or both. Among other constraints, ALLO is more difficult to assay and does not seem to be present at detectable levels in saliva, making it less feasible to measure ALLO alongside $\mathrm{P}$ in psychology research. Future research must include ALLO manipulation and measurement to hone in on the neuropharmacological mechanisms by which P/ALLO may influence affiliation motivation.

\section{A HYPOTHESIS FOR A BROAD ROLE FOR PROGESTERONE AND ALLOPREGNANOLONE IN STRESS COPING AND RECOVERY}

The physiological stress response is essential for life, but can be maladaptive if prolonged (Sapolsky, 2002; Nelson, 2005). Therefore, there are many physiological "brakes" built into the stress system. For example, the HPA axis displays negative feedback: glucocorticoids, its output hormones, turn off production of CRH and ACTH, the hypothalamic and pituitary hormones that lead to production of glucocorticoids. This way, the necessary rise in glucocorticoids that occurs during stress will be kept short, and levels will return to baseline. Since the discovery that GABA-active neurosteroids levels increase during stress, it has been hypothesized that these hormones represent an additional way to down-regulate the stress response (Purdy et al., 1991; Paul and Purdy, 1992). Presumably, as levels of neurosteroids such as ALLO rise, they inhibit neural firing and thereby attenuate anxiety or anxiety-related behavior. As mentioned previously, ALLO also inhibits CRH and AVP gene transcription, thereby directly down-regulating the HPA axis (Patchev et al., 1994, 1996).

Organisms cope with stress behaviorally as well as physiologically. For many mammals, but primates in particular, one important tool for coping with stress is seeking social support. Research in multiple fields has documented the positive or protective health effects of social contact or support in humans, and, conversely, the detrimental effects of isolation or lack of affiliation on mental and physical health. In humans, lack of social support is linked to depression, dysfunctional daily cortisol patterns, worsening of disease states, and mortality (House et al., 1988; Prince et al., 1997; Abercrombie et al., 2004; Boury et al., 2004; TemkinGreener et al., 2004). Social support ameliorates stress responses in laboratory stress paradigms (Heinrichs et al., 2003). Among couples, marital/relationship quality predicts a number of health variables (Coyne et al., 2001; Robles and Kiecolt-Glaser, 2003). In addition, individual differences in implicit affiliation motivation predict long-term health outcomes (McAdams and Vaillant, 1982; Zeldow et al., 1988; McClelland, 1989).

Thus, affiliation and bonding have widespread and powerful effects on health, but the biological mechanisms behind these effects are far from clear. Oxytocin, opioids, and the HPA axis are among the physiological systems implicated in affiliation and bonding and their stress-protective effects (Kalin et al., 1988, 1995; Carter et al., 1992; Fleming et al., 1997; Insel, 1997; UvnasMoberg, 1998b; Depue and Morrone-Strupinsky, 2005). The evidence reviewed above tying P and ALLO to affiliation suggests that these hormones may be another part of the mechanism linking affiliation and health. In particular, the rise in P and ALLO that accompanies stress may function not only to inhibit anxiety on a cellular level (by reducing neuronal activity), but also to promote behavioral strategies to cope with stress, including seeking out social contact and social bonds. In this way, these hormones could underlie both short term (i.e., inhibit the HPA axis) and longer-term (i.e., form and strengthen social connections) adaptive responses to stress (Figure 3). If an individual chooses to seek out others during stress, s/he has the chance to build long-term resources to help buffer the effects of future challenges. Of course, behavioral responses to stress are determined by a host of factors, and hormones generally have modulatory rather than causal effects on behavior. However, P/ALLO increases during stress could be one of many important factors determining the impact of stress on health.

Importantly, there is evidence that an ALLO increase during stress is compromised in individuals with a history of depression (Girdler et al., 2001; Klatzkin et al., 2006b). Decreased or absent P/ALLO responses to stress could lead to both (1) greater anxiety and/or greater HPA axis responses to stress; and (2) decreased propensity to seek affiliation in the face of stress. A lower P/ALLO response to stress could represent both a risk factor for depression, and/or could help explain some of the features of depression, such as worsening of symptoms during stress and decreased social contact. Given growing evidence for the importance of P/ALLO in 


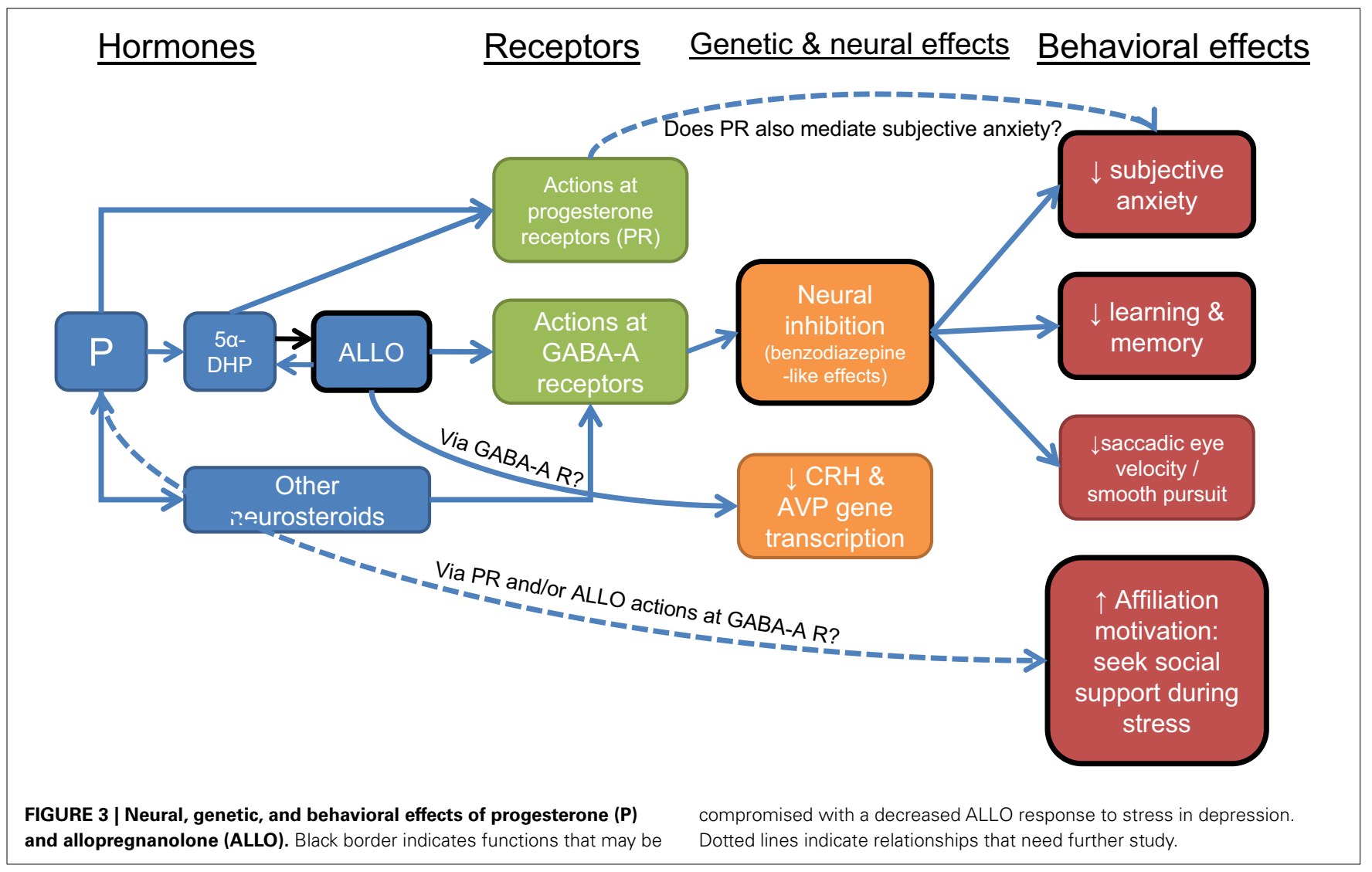

stress, affiliation and affective disorders, it is crucial to elucidate the role these hormones play in emotional processes in both healthy and depressed individuals.

\section{FUTURE DIRECTIONS: UNDERSTANDING P AND ALLO FUNCTION IN STRESS AND PSYCHOPATHOLOGY}

$\mathrm{P}$ and ALLO appear to be stress-responsive, stress-reducing hormones in rodents. In addition, multiple studies have found decreased ALLO in depressed patients compared with healthy controls. To understand the import of these clinical findings, it is necessary to extend our knowledge from laboratory animal research into humans. The evidence reviewed above is largely in support of $\mathrm{P}$ and ALLO increases during stress in humans; there is mixed evidence for effects of these hormones on subjective mood and anxiety.

In addition, evidence is accumulating for a link between $\mathrm{P}$ and motivation to affiliate. These findings suggest the hypotheses that: (1) P/ALLO increases during stress function in part to promote affiliation and bonding as a long-term coping strategy; and (2) diminished P/ALLO responses to stress could be a risk factor for depression, and/or could underlie certain features of depressive disorders, such as less propensity to seek out social contact (Figure 3).

In order to better understand the functions of P and ALLO in stress, and what relevance they may have for psychopathology, further basic research in human subjects is needed in order to (1) establish more firmly whether these hormones are stress-responsive and stress-reducing in humans; (2) uncover clues about cause and effect with regards to ALLO and depression; (3) explore the relevance of $\mathrm{P}$ and ALLO for (stress-related) affiliationseeking; and (4) study how these hormones affect the human brain. This research will by necessity be interdisciplinary, including perspectives from physiological psychology; cognitive neuroscience; clinical psychology; and social/personality psychology. Such basic research will form the groundwork for potential future clinical applications: P and ALLO may emerge as important biological markers of disease states (e.g., risk of developing depression), and drugs designed to impact the synthesis or actions of these neuroactive steroids may have treatment potential.

\section{P AND ALLO: STRESS-RESPONSIVE AND STRESS-REDUCING IN HUMANS?}

The function of $\mathrm{P}$ and ALLO in stress needs to be explored further. Evidence thus far shows that P and ALLO both may be stressresponsive in humans, but conflicting results have been obtained as to whether each hormone increases during stress in men, women (in particular cycle phases), or both (Droogleever Fortuyn et al., 2004; Wirth and Schultheiss, 2006; Childs et al., 2010a; Maner et al., 2010). Future research should explore the effects of various stressors on these hormones, alongside HPA axis hormones, carefully controlling for circadian and other factors and utilizing the best available methods for P and ALLO measurement, ideally quantifying both simultaneously using mass spectrometry. It may be the case such that P/ALLO stress responses are not universal in 
humans, but depend on state factors (e.g., construal of the stressor; menstrual phase) or individual differences (e.g., sex; personality traits). These differences, if they exist, should be further elucidated.

If $\mathrm{P}$ and ALLO are impacted by stress in a healthy population, they then need to be compared in patient groups such as those suffering from Major Depressive Disorder. Although evidence exists that those with a history of depression exhibit lower or absent ALLO responses to stress (Girdler et al., 2001), studies using standardized stress protocols (e.g., the TSST) and with adequate sampling to capture a stress response will help flesh out this evidence. In addition, as MDD has considerable co-morbidity with anxiety disorders and substance abuse, and as these have also been associated with alterations in neurosteroids, P/ALLO responses to stress should be examined in co-morbid groups as well as in MDD patients without other diagnoses.

Finally, more work is needed to elucidate under what circumstances and what doses of P or ALLO impact mood and emotional processing in humans. If these steroids exert paradoxical effects on mood (Andreen et al., 2009), it is important to delineate the doses and conditions under which beneficial mood effects might be obtained by manipulating P or ALLO levels. Use of drugs that block conversion of $\mathrm{P}$ to ALLO, such as finasteride or dutasteride, may help uncover whether mood effects of these hormones are mediated by ALLO's effects on GABA-A receptors; P or $5 \alpha$-DHP's actions at $\mathrm{P}$ receptors (see text footnote 1 ); or both.

\section{ALLO AND DEPRESSION: CAUSE AND EFFECT}

If the evidence continues to support a difference in P/ALLO functioning between healthy individuals and patients, the next question that must be addressed is whether there is a causal relationship between P/ALLO responses and psychopathology. For example, lower P/ALLO responses to stress could be determined by genetic factors and/or early life experiences and could pose a risk factor for development of psychopathology. Alternatively, depression itself could be the cause of diminished P/ALLO responses to stress; the hormonal changes could then lead to exacerbation of the disorder by predisposing the individual to greater anxiety and HPA axis activity during stress, and decreased propensity to seek social support. These two possible cause-effect relationships are not mutually exclusive; each must be tested separately. To test whether reduced P/ALLO contributes to a risk for depression, for example, longitudinal studies in currently healthy, at-risk populations could be employed. This approach could yield important information about new biological risk factors for depression.

It is also unclear whether the reduced ALLO levels seen in MDD are tied to the symptomatology of MDD; that is, whether increasing ALLO levels would alleviate symptoms. In rodent models of depression, ALLO does reduce depression-like behavior (Khisti et al., 2000; Guidotti et al., 2001; Rodriguez-Landa et al., 2007). However, human depression can be successfully treated (with nonpharmacological means) without increased ALLO accompanying the improvement (Schule et al., 2004; Baghai et al., 2005). Longitudinal studies examining basal and stress-responsive P and ALLO levels before depression onset and after recovery can help inform whether pharmacological treatments aimed at increasing ALLO production or activity should be pursued.

\section{P AND ALLO IN AFFILIATION-SEEKING}

The evidence for a relationship between $\mathrm{P}$ and affiliation motivation is still sparse. Future research both in animal models and in humans is needed to delineate this relationship. In particular, in order to establish a causal relationship, hormone manipulation studies are necessary. Elucidation is needed as to whether the proposed $\mathrm{P}$-affiliation relationship is mediated by $\mathrm{P}$ itself, acting at intercellular $\mathrm{P}$ receptors, or mediated by the conversion of $\mathrm{P}$ to ALLO and actions at GABA-A receptors. Further, it is of interest whether this purported P/ALLO-affiliation relationship is disrupted in depression or other disorders. A better understanding of the relationships between stress, affiliation, and hormones could lead to behavioral interventions, e.g., to increase affiliation and social support-seeking, as preventative and adjunct treatment options.

\section{HOW P AND ALLO AFFECT THE HUMAN BRAIN}

There are obvious limitations to what can be understood about the function of hormones in stress, mood, and affiliation only by measuring or manipulating peripheral levels of hormones. In order to uncover the neural mechanisms of the effects of P and ALLO on mood and behavior, brain imaging methods must be employed, along with pharmacological manipulations. One important question is whether GABA activity in the human brain parallels peripheral release of $\mathrm{P}$ during stress. This question might be addressed using positron emission tomography (PET) imaging with radioactive ligands for the GABA-A receptor. Unfortunately, currently only radioligands for the benzodiazepine binding site are available. ALLO appears to bind to a different site, as yet uncharacterized (Brot et al., 1997; Lambert et al., 2003; Akk et al., 2004b). Another approach might be to use proton magnetic resonance spectroscopy (H1-MRS) to gain information regarding GABA concentrations in different brain regions (Epperson et al., 2002, 2006). GABA concentrations may fluctuate in emotion-related brain areas during stress or pharmacological manipulation of P/ALLO.

\section{CONCLUSION}

Neuroscience research in rodents has established a crucial role for $\mathrm{P}$ and ALLO in stress, while clinical research comparing patient groups to healthy controls strongly suggests dysregulation in neurosteroids in affective and other disorders. In order to understand the significance of P/ALLO differences between patients and controls, it is necessary to know more about the basic physiology and psychology of these hormones in humans. The available evidence suggests that, like in rodents, both $\mathrm{P}$ and ALLO increase during stress in humans, but more systematic studies are needed. Although neurosteroids are indirect GABA agonists and appear to cause anxiolysis in rodents, the evidence thus far suggests that P/ALLO administration causes mild (if any) effects on mood and subjective anxiety in humans. In fact, some individuals may respond to P/ALLO with adverse mood effects (Andreen et al., 2009). In contrast, administration of these hormones do exert effects in humans consistent with GABA agonists, such as effects on saccadic eye velocity (Sundstrom et al., 1998; Timby et al., 2006) and on memory (Freeman et al., 1993; van Wingen et al., 2007; Kask et al., 2008). Meanwhile, a growing social psychology literature suggests a connection between $\mathrm{P}$ and motivation for affiliation/social contact (Wirth 
and Schultheiss, 2006; Brown et al., 2009; Maner et al., 2010). $\mathrm{P}$ may be especially responsive to social rejection (Wirth and Schultheiss, 2006; Maner et al., 2010). This connection suggests another possible role for P/ALLO rises in response to stress, namely, to promote social contact as a long-term coping strategy. If so, P/ALLO could be a risk factor for depression in part by way of a decreased propensity to affiliate. Further work is needed to answer these questions, which will require collaboration between researchers in neuroendocrinology, social psychology, and clinical psychology/psychiatry.

\section{ACKNOWLEDGMENTS}

Data shown in Figure 2 were collected in 2007-2009 with Heather C. Abercrombie, Ph.D. and Roxanne M. Hoks at the University

\section{REFERENCES}

Abercrombie, H. C., Giese-Davis, J., Sephton, S., Epel, E. S., Turner-Cobb, J. M., and Spiegel, D. (2004). Flattened cortisol rhythms in metastatic breast cancer patients. Psychoneuroendocrinology 29, 1082-1092.

Akil, H., Watson, S. J., Young, E., Lewis, M. E., Khachaturian, H., and Walker, J. M. (1984). Endogenous opioids: biology and function. Annu. Rev. Neurosci. 7, 223-255.

Akk, G., Bracamontes, J., and Steinbach, J. H. (2004a). Activation of $\mathrm{GABA}(\mathrm{A})$ receptors containing the alpha4 subunit by GABA and pentobarbital. J. Physiol. (Lond.) 556, 387-399.

Akk, G., Bracamontes, J. R., Covey, D. F., Evers, A., Dao, T., and Steinbach, J. H. (2004b). Neuroactive steroids have multiple actions to potentiate GABAA receptors. J. Physiol. (Lond.) 558, 59-74.

Alomary, A. A., Fitzgerald, R. L., and Purdy, R. H. (2001). Neurosteroid analysis. Int. Rev. Neurobiol. 46, 97-115.

Amin, Z., Mason, G. F., Cavus, I., Krystal, J. H., Rothman, D. L., and Epperson, C. N. (2006). The interaction of neuroactive steroids and GABA in the development of neuropsychiatric disorders in women. Pharmacol. Biochem. Behav. 84, 635-643.

Andreen, L., Nyberg, S., Turkmen, S., van Wingen, G., Fernandez, G., and Backstrom, T. (2009). Sex steroid induced negative mood may be explained by the paradoxical effect mediated by GABAA modulators. Psychoneuroendocrinology 34, 1121-1132.

Auger, C. J., and Forbes-Lorman, R. M. (2008). Progestin receptor-mediated reduction of anxiety-like behavior in male rats. PLoS ONE 3, e3606. doi: 10.1371/journal.pone.0003606

Baghai, T. C., di Michele, F., Schule, C., Eser, D., Zwanzger, P., Pasini,
A., Romeo, E., and Rupprecht, R. (2005). Plasma concentrations of neuroactive steroids before and after electroconvulsive therapy in major depression. Neuropsychopharmacol-

Barbaccia, M. L., Roscetti, G., Trabucchi, M., Purdy, R. H., Mostallino, M. C., Concas, A., and Biggio, G. (1997). The effects of inhibitors of GABAergic transmission and stress on brain and plasma allopregnanolone concentrations. Br. J. Pharmacol. 120, 1582-1588.

Barbaccia, M. L., Serra, M., Purdy, R. H., and Biggio, G. (2001). Stress and neuroactive steroids. Int. Rev. Neurobiol. 46, 243-272.

Bicikova, M., Dibbelt, L., Hill, M., Hampl, R., and Starka, L. (1998). Allopregnanolone in women with premenstrual syndrome. Horm. Metab. Res. 30, 227-230.

Bitran, D., Hilvers, R. J., and Kellogg, C. K. (1991). Anxiolytic effects of 3 alpha-hydroxy-5 alpha[beta]pregnan-20-one: endogenous metabolites of progesterone that are active at the GABAA receptor. Brain Res. 561, 157-161.

Bitran, D., Shiekh, M., and McLeod, M. (1995). Anxiolytic effect of progesterone is mediated by the neurosteroid allopregnanolone at brain GABAA receptors. J. Neuroendocrinol. 7, 171-177.

Boury, J. M., Larkin, K. T., and Krummel, D. A. (2004). Factors related to postpartum depressive symptoms in low-income women. Women Health 39, 19-34.

Brambilla, F., Biggio, G., Pisu, M. G., Bellodi, L., Perna, G., BogdanovichDjukic, V., Purdy, R. H., and Serra, M. (2003). Neurosteroid secretion in panic disorder. Psychiatry Res 118, 107-116.

Brot, M. D., Akwa, Y., Purdy, R. H., Koob, G. F., and Britton, K. T. (1997). The ogy 30, 1181-1186.

of Wisconsin (UW) Clinical and Translational Research Core (CTRC), with support from NIH award 1 K08MH07415 to Heather Abercrombie, NIH institutional training grant T32MH18931 which supported Michelle Wirth, and grant 1UL1RR025011 from the Clinical and Translational Science Award (CTSA) program of the NIH National Center for Research Resources, which supported the UW CTRC. The study was approved by the UW Health Sciences Institutional Review Board. All study participants provided informed consent. The author thanks research assistants Cindy Burzinski, Camilia Cenek, Brittany Nanzig, Sean Scherer, and Shefaali Sharma for assistance with data collection; George Nash, Patrick Roseboom, and Ned Kalin for assistance with hormone assays; and Pawel Olszewski for helpful comments on a manuscript draft.

anxiolytic-like effects of the neurosteroid allopregnanolone: interactions with GABA(A) receptors. Eur. J. Pharmacol. 325, 1-7.

Brown, S. L., and Brown, R. M. (2011). Activation of the caregiving system: progesterone as a possible mechanism for linking compassionate behavior to enhanced stress regulation. Paper Presented at Association for Psychological Science's 23rd Annual Meeting, Washington, DC.

Brown, S. L., Fredrickson, B. L., Wirth, M. M., Poulin, M. J., Meier, E. A., Heaphy, E. D., Cohen, M. D. and Schultheiss, O. C. (2009). Social closeness increases salivary progesterone in humans. Horm. Behav. 56, 108-111.

Carter, C. S., Williams, J. R., Witt, D. M. and Insel, T. R. (1992). Oxytocin and social bonding. Ann. N. Y. Acad. Sci. 652, 204-211.

Celotti, F., Melcangi, R. C., and Martini, L. (1992). The 5 alpha-reductase in the brain: molecular aspects and relation to brain function. Front. Neuroendocrinol. 13, 163-215.

Cheney, D. L., Uzunov, D., Costa E., and Guidotti, A. (1995). Gas chromatographic-mass fragmentographic quantitation of 3 alpha-hydroxy-5 alpha-pregnan20-one (allopregnanolone) and its precursors in blood and brain of adrenalectomized and castrated rats. J. Neurosci. 15, 4641-4650.

Childs, E., and de Wit, H. (2009). Hormonal, cardiovascular, and subjective responses to acute stress in smokers. Psychopharmacology (Berl.) 203, 1-12.

Childs, E., Dlugos, A., and De Wit, $\mathrm{H}$. (2010a). Cardiovascular, hormonal, and emotional responses to the TSST in relation to sex and menstrual cycle phase. Psychophysiology 47, 550-559.

Childs, E., Van Dam, N. T., and de Wit, H. (2010b). Effects of acute progesterone administration upon responses to acute psychosocial stress in men. Exp. Clin. Psychopharmacol. 18, 78-86.

Cohen, J., and Cohen, P. (1983). Applied Multiple Regression/Correlation Analysis for the Behavioral Sciences. Hillsdale, NJ: Erlbaum.

Compagnone, N. A., and Mellon, S. H. (2000). Neurosteroids: biosynthesis and function of these novel neuromodulators. Front. Neuroendocrinol. 21, 1-56.

Coyne, J. C., Rohrbaugh, M. J., Shoham, V., Sonnega, J. S., Nicklas, J. M., and Cranford, J. A. (2001). Prognostic importance of marital quality for survival of congestive heart failure. Am. J. Cardiol. 88, 526-529.

da Silva Torres, I. L., Cucco, S. N., Bassani, M., Duarte, M. S., Silveira, P. P., Vasconcellos, A. P., Tabajara, A. S., Dantas, G., Fontella, F. U., Dalmaz, C., and Ferreira, M. B. (2003). Long-lasting delayed hyperalgesia after chronic restraint stress in rats-effect of morphine administration. Neurosci. Res. 45, 277-283.

de Kloet, E. R., Oitzl, M. S., and Joels, M (1999). Stress and cognition: are corticosteroids good or bad guys? Trends Neurosci. 22, 422-426.

de Quervain, D. J., Aerni, A., Schelling, G., and Roozendaal, B. (2009). Glucocorticoids and the regulation of memory in health and disease. Front Neuroendocrinol. 30, 358-370.

de Wit, H., Schmitt, L., Purdy, R. and Hauger, R. (2001). Effects of acute progesterone administration in healthy postmenopausal women and normally-cycling women. Psychoneuroendocrinology 26, 697-710.

Depue, R. A., and Morrone-Strupinsky, J. V. (2005). A neurobehavioral model of affiliative bonding: implications for conceptualizing a human trait of affiliation. Behav. Brain Sci. 28, 313-350; discussion 350-395. 
Dickerson, S. S., and Kemeny, M. E. (2004). Acute stressors and cortisol responses: a theoretical integration and synthesis of laboratory research. Psychol. Bull. 130, 355-391.

Dong, E., Matsumoto, K., Uzunova, V., Sugaya, I., Takahata, H., Nomura, H., Watanabe, H., Costa, E., and Guidotti, A. (2001). Brain 5alphadihydroprogesterone and allopregnanolone synthesis in a mouse model of protracted social isolation. Proc. Natl. Acad. Sci. U.S.A. 98, 2849-2854.

Droogleever Fortuyn, H. A., van Broekhoven, F., Span, P. N., Backstrom, T., Zitman, F. G., and Verkes, R. J. (2004). Effects of PhD examination stress on allopregnanolone and cortisol plasma levels and peripheral benzodiazepine receptor density. Psychoneuroendocrinology 29, 1341-1344.

Dubrovsky, B. (2006). Neurosteroids, neuroactive steroids, and symptoms of affective disorders. Pharmacol. Biochem. Behav. 84, 644-655.

Epperson, C. N., Gueorguieva, R., Czarkowski, K. A., Stiklus, S., Sellers, E., Krystal, J. H., Rothman, D. L., and Mason, G. F. (2006). Preliminary evidence of reduced occipital GABA concentrations in puerperal women: a 1H-MRS study. Psychopharmacology (Berl.) 186, 425-433.

Epperson, C. N., Haga, K., Mason, G. F., Sellers, E., Gueorguieva, R., Zhang, W., Weiss, E., Rothman, D. L., and Krystal, J. H. (2002). Cortical gamma-aminobutyric acid levels across the menstrual cycle in healthy women and those with premenstrual dysphoric disorder: a proton magnetic resonance spectroscopy study. Arch. Gen. Psychiatry 59, 851-858.

Eser, D., Romeo, E., Baghai, T. C., di Michele, F., Schule, C., Pasini, A., Zwanzger, P., Padberg, F., and Rupprecht, R. (2006). Neuroactive steroids as modulators of depression and anxiety. Neuroscience 138, 1041-1048.

Fleming, A. S., Steiner, M., and Corter, C. (1997). Cortisol, hedonics, and maternal responsiveness in human mothers. Horm. Behav. 32, 85-98.

Freeman, E. W., Purdy, R. H., Coutifaris, C., Rickels, K., and Paul, S. M. (1993). Anxiolytic metabolites of progesterone: correlation with mood and performance measures following oral progesterone administration to healthy female volunteers. Neuroendocrinology 58, 478-484.

Friess, E., Tagaya, H., Trachsel, L., Holsboer, F., and Rupprecht, R. (1997). Progesterone-induced changes in sleep in male subjects. Am. J. Physiol. 272, E885-E891.

Frye, C. A., Bayon, L. E., Pursnani, N. K., and Purdy, R. H. (1998). The neurosteroids, progesterone and 3alpha,5alpha-THP, enhance sexual motivation, receptivity, and proceptivity in female rats. Brain Res. 808 , $72-83$.

Frye, C. A., Rhodes, M. E., Petralia, S. M., Walf, A. A., Sumida, K. and Edinger, K. L. (2006). 3alphahydroxy-5alpha-pregnan-20-one in the midbrain ventral tegmental area mediates social, sexual, and affective behaviors. Neuroscience 138, 1007-1014.

Frye, C. A., Walf, A. A., Rhodes, M. E., and Harney, J. P. (2004). Progesterone enhances motor, anxiolytic, analgesic, and antidepressive behavior of wild-type mice, but not those deficient in type 15 alpha-reductase. Brain Res. 1004, 116-124.

Genazzani, A. R., Petraglia, F., Bernardi, F., Casarosa, E., Salvestroni, C., Tonetti, A., Nappi, R. E., Luisi, S., Palumbo, M., Purdy, R. H., and Luisi, M. (1998). Circulating levels of allopregnanolone in humans: gender, age, and endocrine influences. J. Clin. Endocrinol. Metab. 83 2099-2103.

Girdler, S. S., and Klatzkin, R. (2007). Neurosteroids in the context of stress: implications for depressive disorders. Pharmacol. Ther. 116, 125-139.

Girdler, S. S., Straneva, P. A., Light, K. C., Pedersen, C. A., and Morrow, A. L. (2001). Allopregnanolone levels and reactivity to mental stress in premenstrual dysphoric disorder. Biol. Psychiatry 49, 788-797.

Guidotti, A., Dong, E., Matsumoto, K., Pinna, G., Rasmusson, A. M., and Costa, E. (2001). The sociallyisolated mouse: a model to study the putative role of allopregnanolone and 5alpha-dihydroprogesterone in psychiatric disorders. Brain Res. Brain Res. Rev. 37, 110-115.

Harrison, N. L., Majewska, M. D., Harrington, J. W., and Barker, J. L. (1987). Structure-activity relationships for steroid interaction with the gamma-aminobutyric acidA receptor complex. J. Pharmacol. Exp. Ther. $241,346-353$

Harrison, N. L., and Simmonds, M. A. (1984). Modulation of the GABA receptor complex by a steroid anaesthetic. Brain Res. 323, 287-292.

Hashimoto, K., Murakami, K., Takao, T., Makino, S., Sugawara, M. and Ota, Z. (1989). Effect of acute ether or restraint stress on plasma corticotropin-releasing hormone, vasopressin and oxytocin levels in the rat. Acta Med. Okayama $43,161-167$.

Heinrichs, M., Baumgartner, T., Kirschbaum, C., and Ehlert, U. (2003). Social support and oxytocin interact to suppress cortisol and subjective responses to psychosocial stress. Biol. Psychiatry 54 1389-1398.

House, J. S., Landis, K. R., and Umberson, D. (1988). Social relationships and health. Science 241, 540-545.

Insel, T. R. (1997). A neurobiological basis of social attachment. Am. J. Psychiatry 154, 726-735.

Joels, M. (2006). Corticosteroid effects in the brain: U-shape it. Trends Pharmacol. Sci. 27, 244-250.

Johansson, I. M., Birzniece, V., Lindblad, C., Olsson, T., and Backstrom, T. (2002). Allopregnanolone inhibits learning in the Morris water maze. Brain Res. 934, 125-131.

Kalin, N. H., Shelton, S. E., and Barksdale, C. M. (1988). Opiate modulation of separation-induced distress in non-human primates. Brain Res. 440, 285-292.

Kalin, N. H., Shelton, S. E., and Lynn, D. E. (1995). Opiate systems in mother and infant primates coordinate intimate contact during reunion. Psychoneuroendocrinology 20, 735-742.

Karavolas, H. J., Hodges, D. R., and O’Brien, D. J. (1979). In vivo uptake and metabolism of $[3 \mathrm{H}]$ progesterone and $[3 \mathrm{H}] 5$ alpha-dihydroprogesterone by rat CNS and anterior pituitary: tissue concentration of progesterone itself or metabolites? J. Steroid Biochem. 11, 863-872.

Kask, K., Backstrom, T., Nilsson, L. G., and Sundstrom-Poromaa, I. (2008). Allopregnanolone impairs episodic memory in healthy women. Psychopharmacology (Berl.) 199, 161-168.

Khisti, R. T., Chopde, C. T., and Jain, S. P. (2000). Antidepressant-like effect of the neurosteroid 3alphahydroxy-5alpha-pregnan-20-one in mice forced swim test. Pharmacol. Biochem. Behav. 67, 137-143.

Kim, Y. S., Zhang, H., and Kim, H. Y. (2000). Profiling neurosteroids in cerebrospinal fluids and plasma by gas chromatography/electron capture negative chemical ionization mass spectrometry. Anal. Biochem. 277, 187-195

Kirschbaum, C., Pirke, K. M., and Hellhammer, D. H. (1993). The 'Trier Social Stress Test' - a tool for investigating psychobiological stress responses in a laboratory setting. Neuropsychobiology 28, 76-81.

Klatzkin, R. R., Morrow, A. L., Light, K. C., Pedersen, C. A., and Girdler,
S. S. (2006a). Associations of histories of depression and PMDD diagnosis with allopregnanolone concentrations following the oral administration of micronized progesterone. Psychoneuroendocrinology 31, 1208-1219.

Klatzkin, R. R., Morrow, A. L., Light, K. C., Pedersen, C. A., and Girdler S. S. (2006b). Histories of depression, allopregnanolone responses to stress, and premenstrual symptoms in women. Biol. Psychol. 71, 2-11.

Ladurelle, N., Eychenne, B., Denton, D., Blair-West, J., Schumacher M., Robel, P., and Baulieu, E (2000). Prolonged intracerebroventricular infusion of neurosteroids affects cognitive performances in the mouse. Brain Res. 858, 371-379.

Lambert, J. J., Belelli, D., Peden, D. R., Vardy, A. W., and Peters, J. A (2003). Neurosteroid modulation of GABAA receptors. Prog. Neurobiol. 71, 67-80.

Longone, P., Rupprecht, R., Manieri, G. A., Bernardi, G., Romeo, E., and Pasini, A. (2008). The complex roles of neurosteroids in depression and anxiety disorders. Neurochem. Int 52, 596-601.

Lupien, S. J., Maheu, F., Tu, M. Fiocco, A., and Schramek, T. E (2007). The effects of stress and stress hormones on human cognition: implications for the field of brain and cognition. Brain Cogn. 65, 209-237.

Magnaghi, V. (2007). GABA and neuroactive steroid interactions in glia: new roles for old players? $\mathrm{Curr}$. Neuropharmacol. 5, 47-64.

Majewska, M. D., Harrison, N. L. Schwartz, R. D., Barker, J. L., and Paul, S. M. (1986). Steroid hormone metabolites are barbituratelike modulators of the GABA receptor. Science 232, 1004-1007.

Maner, J. K., Miller, S. L., Schmidt, N. B., and Eckel, L. A. (2010). The endocrinology of exclusion: rejection elicits motivationally tuned changes in progesterone. Psychol. Sci. $21,581-588$.

Marx, C. E., Stevens, R. D., Shampine, L. J., Uzunova, V., Trost, W. T., Butterfield, M. I., Massing, M. W., Hamer, R. M., Morrow, A. L., and Lieberman, J. A. (2006). Neuroactive steroids are altered in schizophrenia and bipolar disorder: relevance to pathophysiology and therapeutics. Neuropsychopharmacology 31, 1249-1263.

McAdams, D. P., and Vaillant, G. E. (1982). Intimacy motivation and psychosocial adjustment: a longitudinal study. J. Pers. Assess. 46, 586. 
McClelland, D. C. (1989). Motivational factors in health and disease. Am. Psychol. 44, 675.

Miczek, K. A., Fish, E. W., and De Bold, J. F. (2003). Neurosteroids, GABAA receptors, and escalated aggressive behavior. Horm. Behav. 44, 242-257.

Morrow, A. L. (2007). Recent developments in the significance and therapeutic relevance of neuroactive steroids - Introduction to the special issue. Pharmacol. Ther. 116, 1-6.

Nelson, R. J. (2005). "Stress," in An Introduction to Behavioral Endocrinology, Anonymous (Sunderland, MA: Sinauer Associates), 669-720.

Norberg, L., Wahlstrom, G., and Backstrom, T. (1987). The anaesthetic potency of 3 alpha-hydroxy5 alpha-pregnan-20-one and 3 alpha-hydroxy-5 beta-pregnan-20one determined with an intravenous EEG-threshold method in male rats. Pharmacol. Toxicol. 61, 42-47.

N-Wihlback, A. C., SundstromPoromaa, I., and Backstrom, T. (2006). Action by and sensitivity to neuroactive steroids in menstrual cycle related CNS disorders. Psychopharmacology (Berl.) 186, 388-401.

Onaka, T. (2004). Neural pathways controlling central and peripheral oxytocin release during stress. J. Neuroendocrinol. 16, 308-312.

Parizek, A., Hill, M., Kancheva, R., Havlikova, H., Kancheva, L., Cindr, J., Paskova, A., Pouzar, V., Cerny, I., Drbohlav, P., Hajek, Z., and Starka, L. (2005). Neuroactive pregnanolone isomers during pregnancy. J. Clin. Endocrinol. Metab. 90, 395-403.

Patchev, V.K.,Hassan,A.H.,Holsboer,D. F., and Almeida, O. F.(1996). Theneurosteroid tetrahydroprogesterone attenuates the endocrine response to stress and exerts glucocorticoidlike effects on vasopressin gene transcription in the rat hypothalamus. Neuropsychopharmacology 15, 533-540.

Patchev, V. K., Shoaib, M., Holsboer, F., and Almeida, O. F. (1994). The neurosteroid tetrahydroprogesterone counteracts corticotropinreleasing hormone-induced anxiety and alters the release and gene expression of corticotropinreleasing hormone in the rat hypothalamus. Neuroscience 62, 265-271.

Paul, S. M., and Purdy, R. H. (1992). Neuroactive steroids. FASEB J. 6, 2311-2322.

Pearson Murphy, B. E., and Allison, C. M. (2000). Determination of progesterone and some of its neuroactive ring A-reduced metabolites in human serum. J. Steroid Biochem. Mol. Biol. 74, 137-142.
Pisu, M. G., and Serra, M. (2004). Neurosteroids and neuroactive drugs in mental disorders. Life Sci. 74, 3181-3197.

Porcu, P., O’Buckley, T. K., Alward, S. E., Marx, C. E., Shampine, L. J., Girdler, S. S., and Morrow, A. L. (2009). Simultaneous quantification of GABAergic 3alpha,5alpha/3alpha,5beta neuroactive steroids in human and rat serum. Steroids 74, 463-473.

Prince, M. J., Harwood, R. H., Blizard, R. A., Thomas, A., and Mann, A. H. (1997). Social support deficits, loneliness and life events as risk factors for depression in old age. The Gospel Oak Project VI. Psychol. Med. 27, 323-332.

Purdy, R. H., Morrow, A. L., Moore, P. H. Jr., and Paul, S. M. (1991). Stressinduced elevations of gammaaminobutyric acid type A receptoractive steroids in the rat brain Proc. Natl. Acad. Sci. U.S.A. 88, 4553-4557.

Rasmusson, A. M., Pinna, G., Paliwal, P., Weisman, D., Gottschalk, C., Charney, D., Krystal, J., and Guidotti, A. (2006). Decreased cerebrospinal fluid allopregnanolone levels in women with posttraumatic stress disorder. Biol. Psychiatry 60, 704-713.

Ribeiro, S. C., Kennedy, S. E., Smith, Y. R., Stohler, C. S., and Zubieta J. K. (2005). Interface of physi$\mathrm{cal}$ and emotional stress regulation through the endogenous opioid system and mu-opioid receptors. Prog. Neuropsychopharmacol. Biol. Psychiatry 29, 1264-1280.

Robles, T. F., and Kiecolt-Glaser, J. K. (2003). The physiology of marriage: pathways to health. Physiol. Behav. $79,409-416$

Rodriguez-Landa, J. F., Contreras, C. M., Bernal-Morales, B., GutierrezGarcia, A. G., and Saavedra, M. (2007). Allopregnanolone reduces immobility in the forced swimming test and increases the firing rate of lateral septal neurons through actions on the GABAA receptor in the rat. J. Psychopharmacol. 21, 76-84.

Romeo, E., Strohle, A., Spalletta, G., di Michele, F., Hermann, B., Holsboer, F., Pasini, A., and Rupprecht, R. (1998). Effects of antidepressant treatment on neuroactive steroids in major depression. Am. J. Psychiatry $155,910-913$

Rupprecht, R. (1997). The neuropsychopharmacological potential of neuroactive steroids. J. Psychiatr. Res. 31, 297-314.

Sapolsky, R. M. (2002). "Endocrinology of the stress-response," in
Behavioral Endocrinology, eds J. B. Becker, S. M. Breedlove, D. Crews, and M. M. McCarthy (Cambridge, MA: MIT Press), 409-450.

Schule, C., Di Michele, F., Baghai, T., Romeo, E., Bernardi, G., Zwanzger, P., Padberg, F., Pasini, A., and Rupprecht, R. (2004). Neuroactive steroids in responders and nonresponders to sleep deprivation. Ann N. Y. Acad. Sci. 1032, 216-223.

Schultheiss, O. C., Dargel, A., and Rohde, W. (2003). Implicit motives and gonadal steroid hormones: effects of menstrual cycle phase, oral contraceptive use, and relationship status. Horm. Behav. 43, 293-301.

Schultheiss, O. C., Wirth, M. M. and Stanton, S. J. (2004). Effects of affiliation and power motivation arousal on salivary progesterone and testosterone. Horm. Behav. 46, 592-599.

Serra, M., Sanna, E., Mostallino, M. C., and Biggio, G. (2007). Social isolation stress and neuroactive steroids. Eur. Neuropsychopharmacol. 17, 1-11.

Shu, H. J., Eisenman, L. N., Jinadasa, D., Covey, D. F., Zorumski, C. F. and Mennerick, S. (2004). Slow actions of neuroactive steroids at GABAA receptors. J. Neurosci. 24 6667-6675.

Silvers, J. M., Tokunaga, S., Berry, R. B., White, A. M., and Matthews, D. B. (2003). Impairments in spatial learning and memory: ethanol, allopregnanolone, and the hippocampus. Brain Res. Brain Res. Rev. 43 275-284.

Smith, D. M. (2011). Helping others as a protective factor that promotes physiological resilience to stress. Paper Presented at Association for Psychological Science's 23rd Annual Meeting, Washington, DC

Soderpalm, A. H., Lindsey, S., Purdy, R. H., Hauger, R., and Wit de, H. (2004). Administration of progesterone produces mild sedative-like effects in men and women. Psychoneuroendocrinology 29, 339-354.

Strohle, A., Romeo, E., Hermann, B., Pasini, A., Spalletta, G., di Michele, F., Holsboer, F., and Rupprecht, R. (1999). Concentrations of 3 alpha-reduced neuroactive steroids and their precursors in plasma of patients with major depression and after clinical recovery. Biol. Psychiatry 45, 274-277.

Sundstrom, I., Andersson, A., Nyberg, S., Ashbrook, D., Purdy, R. H., and Backstrom, T. (1998). Patients with premenstrual syndrome have a different sensitivity to a neuroactive steroid during the menstrual cycle compared to control subjects. Neuroendocrinology 67 126-138.

Taylor, S. E., Klein, L. C., Lewis, B. P., Gruenewald, T. L., Gurung, R. A., and Updegraff, J. A. (2000). Biobehavioral responses to stress in females: tend-and-befriend, not fight-or-flight. Psychol. Rev. 107, 411-429.

Temkin-Greener, H., Bajorska, A., Peterson, D. R., Kunitz, S. J., Gross, D., Williams, T. F., and Mukamel, D. B. (2004). Social support and riskadjusted mortality in a frail older population. Med. Care 42, 779-788.

Timby, E., Balgard, M., Nyberg, S., Spigset, O., Andersson, A., Porankiewicz-Asplund, J., Purdy, R. H., Zhu, D., Backstrom, T., and Poromaa, I. S. (2006). Pharmacokinetic and behavioral effects of allopregnanolone in healthy women. Psychopharmacology (Berl.) 186, 414-424.

Uvnas-Moberg, K. (1998a). Antistress pattern induced by oxytocin. News Physiol. Sci. 13, 22-25.

Uvnas-Moberg, K. (1998b). Oxytocin may mediate the benefits of positive social interaction and emotions. Psy choneuroendocrinology 23, 819-835.

Uvnas-Moberg, K., Ahlenius, S., Hillegaart, V., and Alster, P. (1994). High doses of oxytocin cause sedation and low doses cause an anxiolytic-like effect in male rats. Pharmacol. Biochem. Behav. 49, 101-106.

Uzunova, V., Sampson, L., and Uzunov, D. P. (2006). Relevance of endogenous 3alpha-reduced neurosteroids to depression and antidepressant action. Psychopharmacology (Berl.) $186,351-361$

Uzunova, V., Sheline, Y., Davis, J. M. Rasmusson, A., Uzunov, D. P., Costa, E., and Guidotti, A. (1998). Increase in the cerebrospinal fluid content of neurosteroids in patients with unipolar major depression who are receiving fluoxetine or fluvoxamine. Proc. Natl. Acad. Sci. U.S.A. 95, 3239-3244.

Vallee, M., Rivera, J. D., Koob, G. F., Purdy, R. H., and Fitzgerald, R. L. (2000). Quantification of neurosteroids in rat plasma and brain following swim stress and allopregnanolone administration using negative chemical ionization gas chromatography/mass spectrometry. Anal. Biochem. 287, 153-166.

van Broekhoven, F., and Verkes, R. J. (2003). Neurosteroids in depression: a review. Psychopharmacology (Berl.) 165, 97-110.

van Wingen, G., van Broekhoven, F., Verkes, R. J., Petersson, K. M 
Backstrom, T., Buitelaar, J., and Fernandez, G. (2007). How progesterone impairs memory for biologically salient stimuli in healthy young women. J. Neurosci. 27, 11416-11423.

van Wingen, G. A., van Broekhoven, F., Verkes, R. J., Petersson, K. M., Backstrom, T., Buitelaar, J. K., and Fernandez, G. (2008). Progesterone selectively increases amygdala reactivity in women. Mol. Psychiatry 13, 325-333.

Wang, M. D., Wahlstrom, G., and Backstrom, T. (1997). The regional brain distribution of the neurosteroids pregnenolone and pregnenolone sulfate following intravenous infusion. J. Steroid Biochem. Mol. Biol. 62, 299-306.

Wieland, S., Lan, N. C., Mirasedeghi, S., and Gee, K. W. (1991). Anxiolytic activity of the progesterone metabo- lite 5 alpha-pregnan-3 alpha- o1-20one. Brain Res. 565, 263-268.

Wikipedia. (2011). Progesterone. Available at: http://en.wikipedia.org/ wiki/Progesterone [July 18, 2011].

Wirth, M. M., Meier, E. A., Fredrickson, B. L., and Schultheiss, O. C. (2007). Relationship between salivary cortisol and progesterone levels in humans. Biol. Psychol. 74, 104-107.

Wirth, M. M., and Schultheiss, O. C. (2006). Effects of affiliation arousal (hope of closeness) and affiliation stress (fear of rejection) on progesterone and cortisol. Horm. Behav. 50, 786-795.

Wolthers, B. G., and Kraan, G. P. (1999). Clinical applications of gas chromatography and gas chromatography-mass spectrometry of steroids. J. Chromatogr. A 843, 247-274.
Zeldow, P. B., Daugherty, S. R., and McAdams, D. P. (1988). Intimacy, power, and psychological well-being in medical students. J. Nerv. Ment. Dis. 176, 182.

Zhu, D., Wang, M. D., Backstrom, T., and Wahlstrom, G. (2001). Evaluation and comparison of the pharmacokinetic and pharmacodynamic properties of allopregnanolone and pregnanolone at induction of anaesthesia in the male rat. Br. J. Anaesth. 86, 403-412.

Zimmerberg, B., Brunelli, S. A., and Hofer, M. A. (1994). Reduction of rat pup ultrasonic vocalizations by the neuroactive steroid allopregnanolone. Pharmacol. Biochem. Behav. 47, 735-738.

Conflict of Interest Statement: The author declares that the research was conducted in the absence of any commercial or financial relationships that could be construed as a potential conflict of interest.

Received: 17 June 2011; accepted: 28 July 2011; published online: 11 August 2011. Citation: Wirth MM (2011) Beyond the HPA axis: progesterone-derived neuroactive steroids in human stress and emotion. Front. Endocrin. 2:19. doi: 10.3389/fendo.2011.00019

This article was submitted to Frontiers in Neuroendocrine Science, a specialty of Frontiers in Endocrinology.

Copyright $(\odot 2011$ Wirth. This is an openaccess article subject to a non-exclusive license between the authors and Frontiers Media SA, which permits use, distribution and reproduction in other forums, provided the original authors and source are credited and other Frontiers conditions are complied with. 